Original Article

\title{
Success Rate of Endoscopic Third Ventriculostomy (ETV) in Non- Communicating Hydrocephalus in Pediatric Age Group
}

\author{
Sanaullah Pathan ${ }^{1}$, Riaz Ahmed Raja ${ }^{2}$, Peer Asad Aziz ${ }^{1}$, Suhail Ahmed Aghani \\ Abdul Rauf Memon², Mubarak Hussain ${ }^{2}$ \\ ${ }^{1}$ Department of Neurosurgery, Liaquat University Hospital (LUH), Hyderabad \\ ${ }^{2}$ Liaquat University of Medical \& Health Sciences, Jamshoro - Pakistan.
}

\begin{abstract}
Objective: To evaluate success rate of the endoscopic third Ventriculostomy (ETV) in non-communicating type of hydrocephalus in pediatric age group.

Material and Methods: This study was carried in the department of neurosurgery at Liaquat university hospital, Jamshoro in which an endoscopic third Ventriculostomy procedure was performed in patients $(\mathrm{n}=$ 55) with non-communicating hydrocephalus from October 2016 to April 2017. Post-operative follow-up was done on the $15^{\text {th }}$ day post-operative to assess clinical and radiological improvement.
\end{abstract}

Results: 55 patients were included in this study, 26 (47.27\%) males and 29 (52.73\%) females. The mean age was 3.96 years. The most common etiology was aqueductal stenosis 28 (50.90\%) patients followed by posterior fossa tumors in $18(32.72 \%)$ patients. The operative technique was successful in 41 (74.55\%) patients. Out of 41 successful patients, 34 (82.92\%) patients had clinical as well as radiological improvement whereas 7 (17.07\%) patients had clinical improvement only.

Conclusion: The success rate of ETV was $74.55 \%$ in the non-communicating hydrocephalus in the pediatric age group in our study. Endoscopic third Ventriculostomy is an effective treatment for non-Communicating hydrocephalus in pediatric age groups by diversion of CSF intracranially. This procedure provides shunt freedom and can be used alternative to shunts in pediatric age groups with non-communicating hydrocephalus.

Keywords: Endoscopic Third Ventriculostomy (ETV), Non-Communicating Hydrocephalus, Pediatric age groups, Cerebrospinal Fluid.

Corresponding Author: Sanaullah Pathan

Liaquat University Hospital, Hyderabad

Email: sanSun_786@hotmail.com

Date of Submission: 05-05-2021

Date of Revision: 06-06-2021

Date of Online Publishing: 14-06-2021

Date of Print: 30-06-2021
DOI: $10.36552 /$ pjns.v25i2.544

\section{INTRODUCTION}

Hydrocephalus is one of the commonest problems in the field of neurosurgery which occurs as a pathological expansion of the 
ventricular system of the brain with disturbance of intracranial fluid hydrodynamics among different compartments of the brain including CSF, brain and blood, with an estimated prevalence of $1-1.5 \%{ }^{1,2}$ In communicating hydrocephalus absorption of CSF is reduced at the arachnoid granulations and in noncommunicating hydrocephalus blockage of CSF flow occur before arachnoid granulations. ${ }^{3}$ It gets managed by diverting the CSF with ventriculoperitoneal shunts or third ventriculostomies. ${ }^{3} \quad$ Endoscopic third Ventriculostomy (ETV) is a minimally invasive procedure that involves a small perforation (stoma) below the third ventricle allowing passage of 3rd ventricular CSF to pass to interpeduncular and pre-pontine cisterns thus relieving ventricular pressure. ${ }^{4-6}$

ETV has gained popularity as a minimal invasive treatment option for non-communicating hydrocephalous in adults and children and advocated in studies to be the first choice for non-communicating hydrocephalus. ${ }^{7-9}$ Ventriculoperitoneal shunt (VPS) is device related an open surgical procedurecommonly used to treat non communicating hydrocephalus within-country whereas, ETVdoes not introduce any devicerelated complications, which often needs repeated surgical revisions. ${ }^{10,11}$ Success rate of ETV varies in literature from $30-90 \% .^{12-14}$ Postoperative clinical outcome has great value to assess the success of procedure rather than radiological improvement which does not always occur. ${ }^{15}$ On the other hand, the other studies reported that the likelihood of failed outcome during first sixteen post-operative days could be up to $90 \% .{ }^{16,17}$ Majority of studies describe the success rate of ETV in both populations of adult and pediatric age groups. Therefore, this study was designed to determine the success of endoscopic third Ventriculostomy in pediatric age group.

\section{MATERIAL AND METHODS}

\section{Study Design and Setting}

This study was carried out from October 2016 to April 2017 in the Department of Neurosurgery at Liaquat university hospital, Jamshoro. In this study, 55 patients were included meeting inclusion and exclusion criteria, and admitted through outpatient department.

\section{Sample Size}

Consecutive non-probability sampling technique was used. The sample size was calculated using WHO sample size calculator. Success rate reported in a study ${ }^{12}$ to be $71 \%$. Using a $12 \%$ margin of error and $95 \%$ level of confidence, the maximum sample size required was 55 participants. Study approval was taken from the hospital's ethical and research committee and research evaluation unit of college of physicians and surgeons (CPSP) Pakistan. The patient's attendants were informed about the procedure along with pros and cons and informed consent was taken from the patient's attendants.

\section{Inclusion Criteria}

Pediatric age patients from 0.5 years to 12 years of age were included in this study with noncommunicating type of hydrocephalus.

\section{Exclusion Criteria}

Patients below 0.5 years of age, mentally retarded, and Patients with non-communicating hydrocephalus having infective or hemorrhagic CSF, were excluded from this study.

\section{Operative Technique}

Patients were kept in a supine position with the head placed in a horseshoe headrest. The surgeon stands behind the patient along with the assistant and scrub nurse on the right side. The screen was placed on the left side. Karl Storz 
endoscopic system for ETV was used. An inverted U-shaped incision was given above Kocher's point. Burr hole was made at Kocher's point. Dura opened with a U-shaped incision and a rigid endoscope was introduced into the lateral ventricle. Foramen of Monro was identified by choroid plexus, thalamostriate and septal veins to get entry into the third ventricle. Stoma was formed between mammillary bodies and infundibular recess in the floor of the third ventricle. The aim was to dilate stoma including Liliequist membrane up to $5 \mathrm{~mm}$ and stoma dilation was done by using Fogarty 4Fr balloon catheter.

\section{Data Collection}

The data collection was collected through a predesigned proforma for clinical history and clinical examinations. The radiological investigations were done including $\mathrm{CT}$ scan or MRI brain pre-operatively, and CT scan brain plain post-operatively, on the $15^{\text {th }}$ day of surgery. Success was defined as a clinical improvement with or without radiological improvement assessed on CT scan brain plain on post-operative day $15^{\text {th }}$ of endoscopic third Ventriculostomy. Surgery was performed by a single consultant neurosurgeon having experience of more than 10 years post-fellowship.

\section{Follow-Up and Post-Operative Findings}

Post-operative follow-up was done on the $15^{\text {th }}$ day post-operative to assess clinical and radiological improvement. Clinical findings were collected included headache (which was assessed on Wong-Baker faces pain rating scale), vomiting, visual disturbance, irritability, bulging fontanelle, and gait disturbance. Post-operative CT scan was done on the 15th-day post operatively to assess radiological improvement in the form of loss of effacement (reappearance) of cortical sulci. Patient care was taken as per ward guidelines and protocol.

\section{Data Analysis}

All statistical analysis was done by using SPSS version 25. A Chi-square test was applied to compare the age groups with the success of procedure for the significant or insignificant results.

\section{RESULTS}

\section{Gender Distribution}

26 (47.27\%) patients were males and 29 (52.73\%) patients were females. The male to female ratio of the patients was 0.89:1.

\section{Age Distribution}

55 patients were included in this study. The mean age of the patients was $3.96 \pm 3.03$ years with minimum and maximum ages of $0.5 \& 10$ years, respectively.

\section{Etiology of Non-Communicating Hydrocephalus}

Among 55 patients, 28 (50.90\%) patients had aqueductal stenosis, 18 (32.72\%) patients had posterior fossa tumors, 7 (12.72\%) patients had malfunctioning shunts and 2 (3.63\%) patients had pineal tumors (Table 1).

Table 1: Etiology of non-communicating hydrocephalus in patients undergone ETV $(\mathrm{N}=55)$.

\begin{tabular}{lcc} 
Etiology & $\begin{array}{c}\text { Number of } \\
\text { Patients }\end{array}$ & Percentage \\
Aqueductal stenosis & 28 & $50.90 \%$ \\
posterior fossa tumors & 18 & $32.72 \%$ \\
Malfunctioning shunts & 7 & $12.72 \%$ \\
Pineal tumors & 2 & $3.63 \%$ \\
\hline
\end{tabular}

\section{Success of Procedure}

Out of 55 patients, the operative technique was successful in 41 (74.55\%) patients and it was not 
successful in $14(25.45 \%)$ patients. Out of 41 successful patients, $34(82.92 \%)$ had clinical as well as radiological improvements postoperatively, whereas 7 (17.07\%) patients had the clinical improvement only (Figure 1).

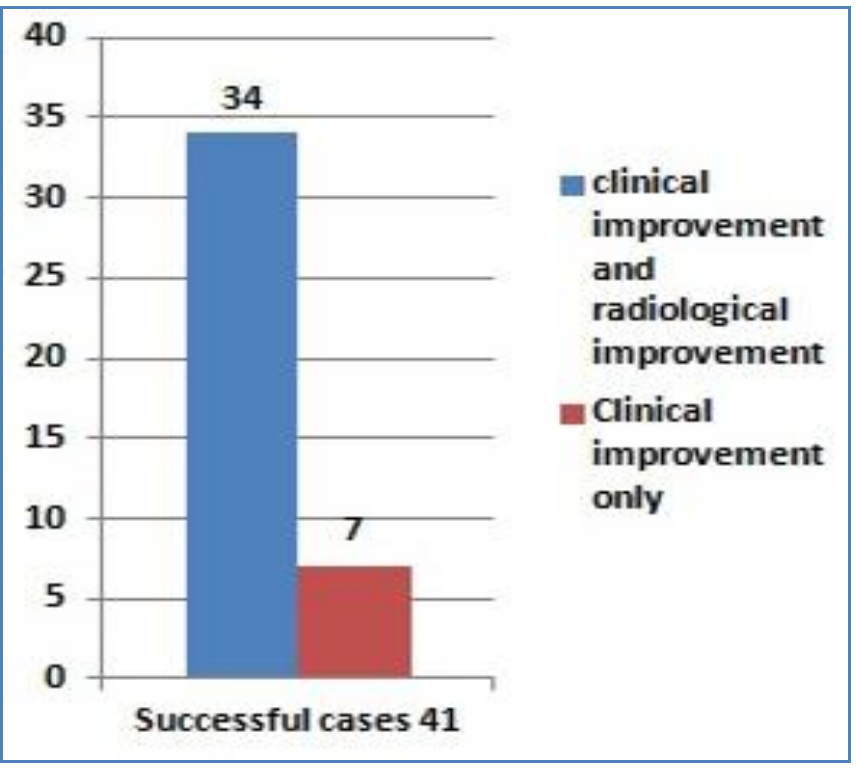

Figure 1: The clinical and radiological improvements $\mathrm{v} / \mathrm{s}$ clinical improvement only in successful cases $(N=41)$.

\section{Comparison of Age with Success of Procedure}

In children of age $0.5-1$ years, the success was achieved in 3 patients (42.85\%) out of 7 patients, in children of age $>1-5$ years, the success was achieved in 24 patients $(77.41 \%)$ out of 31 patients and in children with $>5-10$ years of age, the success was achieved in 14 patients (82.35\%) out of 17 patients (Table 2). Statistically,

Table 2: Comparison of age with success of procedure.

\begin{tabular}{|lcrrrl} 
& & \multicolumn{2}{c}{ Successful } & Total & Statistics \\
& & Yes & No & & \\
Age & $0.5-1$ & 3 & 4 & $\mathbf{7}$ & p value: \\
(Years) & $>1-5$ & 24 & 7 & $\mathbf{3 1}$ & $0.116>0.050$ \\
& $>5-10$ & 14 & 3 & $\mathbf{1 7}$ & (insignificant) \\
\multicolumn{2}{c}{ Total } & $\mathbf{4 1}$ & $\mathbf{1 4}$ & $\mathbf{5 5}$ & $\chi^{2}=4.384$ \\
\hline
\end{tabular}

an insignificant difference was found between the age with success i.e. $p$-value $=0.116>0.050$.

\section{DISCUSSION}

Hydrocephalus is common in pediatric patients. Neurosurgeons have been using endoscopes to treat the hydrocephalus from $20^{\text {th }}$ century. In 1918, choroid plexectomy was performed by Walter Dandy who pioneered the procedure in very few patients with communicating hydrocephalus. A Urologist William Mixter performed the first-ever Endoscopic third Ventriculostomy (ETV). By putting up a new communication channel between the 3rd ventricle and the subarachnoid space on the floor of the 3rd ventricle, ETV aims to relieve the ventricular pressure. $^{18}$ The ETV can have a success of up to $90 \% .^{12-14}$ Some studies have also shown a $90 \%$ failure rate within 16 days, too. ${ }^{16,17}$

In our study, on pediatric non-communicating hydrocephalus, we achieved a success rate of $74 \%$. That's 41 out of 55 total patients. Other studies have shown results that are presented below. In one study of 155 patients, Ali et al $^{12}$ reported a success rate of $71 \%$ after ETV in noncommunicating hydrocephalus, almost near to the success rate of this study (74.55\%). The procedure was considered successful by clinical improvement with and without radiological improvement. $^{12}$ Nikolai et $\mathrm{al}^{19}$ operated on 100 cases and found success in 76 cases of noncommunicating hydrocephalus. They found it effective in the treatment of non-communicating hydrocephalus due to aqueductal stenosis and space-occupying lesions. The success rate is very comparable to our study. Stachura et $\mathrm{al}^{20}$ observed clinical improvement in $77.1 \%$ after ETV in patients with non-communicating hydrocephalus and found best results of ETV in aqueductal stenosis. Haq et $\mathrm{al}^{2}$ found ETV to be effective in $78.4 \%$ of patients with noncommunicating hydrocephalus. Results in both studies are close to this study with a success rate 
of $74.55 \%$. Different success rates of $71 \%, 85 \%$, $89.7 \%$, and $64 \%$ was observed in infants varying in ages with the youngest infant being 1 month old. ${ }^{21-23}$

Duru et $\mathrm{al}^{24}$ reported an $80 \%$ success rate in obstructive hydrocephalus. The success rate is slightly higher than the success rate of this study of $74.55 \%$. Gangemi et al $^{14}$ reported a success rate of $87.1 \%$ after ETV in 140 patients having non-communicating $\mathrm{HCP}$, a multi-centric study carried out in 4 Italian centers. The success rate is much higher than the success rate of this study. In Idowu et al series, which was done in pediatric patients below 6 years, the success rate of VP shunt (91.7\%) was insignificantly superior to ETV (89.7\%). ETV required short anesthesia, used less operative time, hospital stay, cost, and did not produce shunt device-related complications. The success rate of $89.7 \%$ in this study is higher than our study. ${ }^{25}$ Even with posterior fossa tumors, ETV has brought $90 \%$ results similar to brain stem gliomas with HCP (hydrocephalus). ${ }^{26-30}$ Success rates are much higher than our study.

Fritsch et al $^{31}$ reported a 39\% ETV success rate and divided patients with hydrocephalus into 3 groups (obstructive hydrocephalus, communicating hydrocephalus, and myelomeningocele). This study shows a $100 \%$ success rate in obstructive hydrocephalus and only $10 \%$ in communicating hydrocephalus and $50 \%$ with myelomeningocele. The cause of hydrocephalus has a huge bearing on the success of ETV. Jones ${ }^{32}$ in 1990 had the lowest 50\% success rate as shown in his published work.

\section{CONCLUSION}

In our study, the success rate of ETV was $74.55 \%$ in non-communicating hydrocephalus in the pediatric age group. Endoscopic third Ventriculostomy is an effective and profound procedure for the treatment of hydrocephalus by diversion of CSF intracranially. This procedure provides shunt freedom and can be used alternative to shunts in the pediatric age groups.

\section{REFERENCES}

1. Orešković $D$, Radoš $M$, Klarica $M$. New Concepts of Cerebrospinal Fluid Physiology and Development of Hydrocephalus. Pediatr Neurosurg. 2017; 52 (6): 417-425.

2. UI Haq MI, Khan SA, Raja RA, Ahmed E. Efficacy of endoscopic third ventriculostomy in noncommunicating hydrocephalus. J Ayub Med Coll Abbottabad, 2012; 24 (2): 144-6.

3. Deopujari CE, Karmarkar VS, Shaikh ST. Endoscopic Third Ventriculostomy: Success and Failure. J Korean Neurosurg Soc. 2017; 60 (3): 306-314.

4. Demerdash A, Rocque BG, Johnston J, Rozzelle CJ, Yalcin B, Oskouian $R$, et al. Endoscopic third ventriculostomy: A historical review. $\mathrm{Br}$ J Neurosurg. 2017; 31 (1): 28-32.

5. Greitz D. Paradigm shift in hydrocephalus research in legacy of Dandy's pioneering work: rationale for third ventriculostomy in communicating hydrocephalus. Child Ner Syst. 2007; 23 (5): 487.

6. Jallo GI, Kothbauer KF, Abbott IR. Endoscopic third ventriculostomy. Neurosurg Focus, 2005; 19 (6): 14.

7. Baykan N, Isbir O, Gerçek A, Dagçnar A, Özek MM. Ten years of experience with pediatric neuroendoscopic third ventriculostomy: features and perioperative complications of 210 cases. J Neurosurg Anesthesiol. 2005; 17 (1): 33-7.

8. Moorthy R, Rajshekhar V. Endoscopic third ventriculostomy for hydrocephalus: a review of indications, outcomes, and complications. Neurol India, 2011; 59 (6): 848.

9. Sarmast A, Khursheed N, Ramzan A, et al. Endoscopic Third Ventriculostomy in Noncommunicating Hydrocephalus: Report on a Short Series of 53 Children. Asian J Neurosurg. 2019; 14 (1): 35-40.

10. Kulkarni AV, Drake JM, Kestle JR, Mallucci CL, Sgouros S, Constantini $S$, et al. Endoscopic third ventriculostomy vs cerebrospinal fluid shunt in the treatment of hydrocephalus in children: a propensity score-adjusted analysis. Neurosurg. 2010; 67 (3): 588-93.

11. Choudhary A, Sobti S, Zambre S, Bhaskar S. 
Endoscopic third ventriculostomy in failed ventriculoperitoneal shunt in pediatric population. Asian J Neurosurg. 2020; 15 (4): 937-40.

12. Ali $M$, Usman $M$, Khan $Z$, Khan KM, Hussain $R$, Khanzada K. Endoscopic third ventriculostomy for obstructive hydrocephalus. J Coll Physicians Surg Pak. 2013; 23 (5): 338-41.

13. Jenkinson $M D$, Hayhurst $C$, Al-Jumaily $M$, Kandasamy J, Clark S, Mallucci CL. The role of endoscopic third ventriculostomy in adult patients with hydrocephalus: Clinical article. J Neurosurg. 2009; 110 (5): 861-6.

14. Gangemi M, Mascari $C$, Maiuri F, Godano U, Donati $\mathrm{P}$, Longatti P. Long-term outcome of endoscopic third ventriculostomy in obstructive hydrocephalus. Minim Invasive Neurosurg. 2007; 50 (05): 265-69.

15. Buxton N, Turner B, Ramli N, Vloeberghs $M$. Changes in third ventricular size with neuroendoscopic third ventriculostomy: a blinded study. J Neurol, Neurosurg \& Psychiatry, 2002; 72 (3): 385-7.

16. Warf BC, Campbell JW. Combined endoscopic third ventriculostomy and choroid plexus cauterization as primary treatment of hydrocephalus for infants with myelomeningocele: long-term results of a prospective intent-to-treat study in 115 East African infants: Clinical article. J Neurosurg: Pediatr. 2008; 2 (5): 310-6.

17. Melot $A$, Curey-Lévêque $S$, Derrey $S$, Gérardin $E$, Borden A, Fréger $P$, et al. Endoscopic 3rd ventriculocisternostomy: Procedural complications and long-term dysfunctions? Neurochir. 2013; 59 (4): 165-70.

18. Dandy WE. Extirpation of the choroid plexus of the lateral ventricles in communicating hydrocephalus. Annals Surg. 1918; 68 (6): 569.

19. Hopf NJ, Grunert P, Fries G, Resch K, Perneczky A. Endoscopic third ventriculostomy: outcome analysis of 100 consecutive procedures. Neurosurg. 1999; 44 (4): 795-804.

20. Stachura K, Grzywna E, Kwinta BM, Moskała MM. Endoscopic third ventriculostomy-effectiveness of the procedure for obstructive hydrocephalus with different etiology in adults. Videosurg Other Miniinvasive Tech. 2014; 9: 586-95.

21. Javadpour M, Mallucci C, Brodbelt A, Golash A, May P. The impact of endoscopic third ventriculostomy on the management of newly diagnosed hydrocephalus in infants. Pediatr Neurosurg. 2001; 35 (3): 131-5.

22. Gorayeb RP, Cavalheiro S, Zymberg ST. Endoscopic third ventriculostomy in children younger than 1 year of age. J Neurosurg: Pediatr. 2004; 100 (5): 427-9.

23. Choi JU, Kim DS, Kim SH. Endoscopic surgery for obstructive hydrocephalus. Yonsei Med J. 1999; 40 (6): 600-7.

24. Duru S, Peiro JL, Oria M, Aydin E, Subasi C, Tuncer $C$, et al. Successful endoscopic third ventriculostomy in children depends on age and etiology of hydrocephalus: outcome analysis in 51 pediatric patients. Child's Nerv Syst. 2018; 34 (8): 1521-8.

25. Idowu O, Falope L, Idowu A. Outcome of endoscopic third ventriculostomy and Chhabra shunt system in noncommunicating non-tumor childhood hydrocephalus. J Pediatr Neurosci. 2009; 4 (2): 66.

26. Tamburrini G, Pettorini B, Massimi L, Caldarelli M, Di Rocco C. Endoscopic third ventriculostomy: the best option in the treatment of persistent hydrocephalus after posterior cranial fossa tumour removal? Child Nerv Syst. 2008; 24 (12): 1405.

27. Fritsch MJ, Doerner L, Kienke S, Mehdorn HM. Hydrocephalus in children with posterior fossa tumors: role of endoscopic third ventriculostomy. J Neurosurg: Pediatr. 2005; 103 (1): 40-2.

28. Klimo Jr P, Goumnerova LC. Endoscopic third ventriculocisternostomy for brainstem tumors. J Neurosurg: Pediatr. 2006; 105 (4): 271-4.

29. Mohanty A, Biswas A, Satish S, Vollmer DG. Efficacy of endoscopic third ventriculostomy in fourth ventricular outlet obstruction. Neurosurg. 2008; 63 (5): 905-14..

30. El-Ghandour NM. Endoscopic third ventriculostomy versus ventriculoperitoneal shunt in the treatment of obstructive hydrocephalus due to posterior fossa tumors in children. Child Nerv Syst. 2011; 27 (1): 117-26.

31. Fritsch $M J$, Kienke $S$, Ankermann $T$, Padoin $M$, Mehdorn HM. Endoscopic third ventriculostomy in infants. J Neurosurg: Pediatr. 2005; 103 (1): 50-3.

32. Jones R, Stening W, Brydon M. Endoscopic third ventriculostomy. Neurosurg. 1990; 26 (1): 86-92. 


\section{Additional Information}

Disclosures: Authors report no conflict of interest.

Ethical Review Board Approval: The study was conformed to the ethical review board requirements.

Human Subjects: Consent was obtained by all patients/participants in this study.

\section{Conflicts of Interest:}

In compliance with the ICMJE uniform disclosure form, all authors declare the following:

Financial Relationships: All authors have declared that they have no financial relationships at present or within the previous three years with any organizations that might have an interest in the submitted work.

Other Relationships: All authors have declared that there are no other relationships or activities that could appear to have influenced the submitted work.

\section{AUTHORS CONTRIBUTIONS}

\begin{tabular}{|l|l|l|}
\hline Sr.\# & Author's Full Name & Intellectual Contribution to Paper in Terms of: \\
\hline 1. & Sanaullah Pathan & Study design and methodology. \\
\hline 2. & Riaz Ahmed Raja & Paper writing and data calculations. \\
\hline 3. & Peer Asad Aziz & Data collection and calculations. \\
\hline 4. & Suhail Ahmed Aghani & Analysis of data and interpretation of results etc. \\
\hline 5. & Abdul Rauf Memon & Literature review and referencing. \\
\hline 6. & Mubarak Hussain & Analysis of data and quality insurer. \\
\hline
\end{tabular}

